\title{
Transformaciones familiares y política social en el México contemporáneo
}

\author{
Blanca Mirthala Tamez Valdez \\ Universidad Autónoma de Nuevo León, México
}

Resumen

El documento desarrolla un análisis de la situación familiar enfrentada durante las últimas décadas en México, en particular de las transformaciones sociales y su vínculo con la heterogeneidad de los grupos familiares, a partir de una serie de categorías analíticas centradas en las estrategias familiares que dan cuenta de la vida cotidiana, retomando para ello la propuesta de Mallardi (2018) en torno a: a) estrategias destinadas a la obtención de los recursos de subsistencia, b) estrategias vinculadas a la organización del cuidado, c) estrategias habitacionales vinculadas a las condiciones de vida, d) estrategias asociadas a los procesos de salud-enfermedad y e) estrategias de socialización, aprendizaje y uso del tiempo libre.

Dichas estrategias son abordadas como categorías de análisis, por lo cual su operacionalización es realizada partiendo de la revisión y reflexión respecto a algunos de los principales cambios observados durante las últimas décadas en México; asimismo, se analiza la manera en que esas transformaciones se encuentran atravesadas por una serie de determinantes sociales, particularmente las de género y clase. Otro aspecto que se analiza es la relación de las transformaciones familiares observadas con las políticas sociales dirigidas a los grupos familiares. El análisis presentado, sin ser exhaustivo, muestra la manera en que los elementos señalados y su vinculación llegan a impactar la vida cotidiana de las familias durante las últimas décadas. De esa manera, la vida cotidiana de los grupos familiares muestra una serie de tensiones, ambivalencias y contradicciones derivadas en gran parte de la relación presente entre las presiones ejercidas, por un lado, desde la propia política social implementada y con ello las demandas y mandatos generados desde su contexto sociohistórico, económico y político. Así como, por otro lado, las crecientes necesidades materiales y subjetivas de sus miembros, las cuales exigen respuestas inmediatas que brinden las posibilidades mínimas para la sobrevivencia del grupo familiar.

Palabras clave

Transformaciones familiares; vida cotidiana; políticas

Códigos JEL: H5, D63, D78, I38, K36

\author{
FAMILY TRANSFORMATIONS AND SOCIAL POLICY IN \\ CONTEMPORARY MEXICO
}

\section{Abstract}

The document develops an analysis of the family situation faced during the last decades in Mexico, particularly in the social transformation and their connection with the heterogeneity of the family groups, based on a series of analytical categories focused on family strategies that point out their daily life, taking up the proposal of Mallardi (2018) around: a) strategies aimed at obtaining subsistence resources, b) strategies linked to the specialized care, c) room strategies linked to the conditions life, d) strategies associated with health-disease processes and e) strategies for socialization, learning and use of free time.

These strategies are approached as categories of analysis, for which their operationalization is carried out based on the review and reflection regarding some of the main changes observed during the last decades in Mexico; as well as the way in which these transformations are traversed by a series of social determinants, particularly those of gender and class, as well as their relationship with social policies directed at family groups. The analysis presented, without being exhaustive, shows the way in which the indicated elements and their linkage come to impact the daily life of families during the last decades.

In this way, the daily life of family groups shows a series of tensions, ambivalences and contradictions derived to a large extent from the present relationship between the pressures exerted, on the one hand, from the social policy itself implemented and with it the demands and mandates generated from their socio-historical, economic and political context. On the other hand, the growing material and subjective needs of its members, which demand immediate responses that provide the minimum possibilities for the survival of the family group.

Keywords

Family transformations; daily life; politics

JEL codes: H5, D63, D78, I38, K36

Fecha de recepción del original: 15 de febrero de 2021; versión definitiva: 12 de agosto de 2021.

Blanca Mirthala Tamez Valdez, Universidad Autónoma de Nuevo León. Posgrado de la Facultad de Trabajo Social y Desarrollo Humano. Ciudad Universitaria s/n San Nicolás de los Garza, Nuevo León, México.

Tel.: +52 8126842224; E-mail: blancamtamez@hotmail.es y blanca.tamezvl@uanl.edu.mx; ORCID ID: https://orcid.org/0000-0003-4237-2294. 


\section{Transformaciones familiares y política social en el México contemporáneo}

Blanca Mirthala Tamez Valdez

Universidad Autónoma de Nuevo León, México

1. Introducción

Cuando se habla de familia y particularmente de transformaciones familiares suele señalarse la necesidad de incorporar el tema de la gran diversidad presente en las últimas décadas en torno a los arreglos familiares, especialmente cuando la mirada está centrada en las estructuras o formas que adquieren las mismas, su organización, participantes y distribución de roles y/o tareas entre ellos. Esta diversidad, ampliamente discutida entre los especialistas del tema, alude por un lado al abanico presente entre ellas, así como a las transformaciones observadas entre las mismas (Arriagada, 2007: Ripol, 2001; De Risso, 2001, Ribeiro, 2010). Las transformaciones familiares se encuentran íntimamente vinculadas con los cambios y transiciones demográficas, económicas y sociales; que a su vez están influidos por las del país en cuestión.

Por otro lado, suele aludirse a las dinámicas familiares, como la manera en que se establecen relaciones entre los miembros, el modo en que se conciertan la comunicación y la distribución de tareas, recursos, roles y posiciones entre los miembros; situación en la que se asume como lógica y esperada la diversidad observada, en tanto alude a particularidades derivadas de un gran abanico de posibilidades. Sin embargo, estructura y dinámica suelen verse como elementos separados y divergentes de lo que en realidad constituye una misma unidad, en la que los primeros refieren al aspecto de forma y los segundos al de contenido o fondo; cuando en realidad constituyen elementos intrincados que son parte de un todo complejo, en el cual se determinan mutuamente de manera dialéctica en la realidad familiar.

Ello ocurre en medio de múltiples tensiones y ambivalencias respecto a la presencia de dos tipos de presión continua, una interna relacionada con las necesidades tanto objetivas como subjetivas de los miembros de la familia, lo cual implica gestionar las condiciones necesarias para cubrir tanto las necesidades materiales o de sustento, así como aquellas relacionadas con la identidad y con las necesidades de afecto, por lo cual se vincula a tiempos y espacios determinados, así como a tareas y actividades a realizar. Lo anterior, desde una mirada crítica tiene como principal fin el garantizar la reproducción física y social de sus miembros, siendo ello incorporado en la subjetividad de los individuos y evidenciándose en la vida cotidiana de los hogares (Mallardi, 2018).
El otro tipo de presión proviene principalmente del exterior, en términos de su inclusión en un determinado contexto económico, social y político, desde el cual recibe múltiples demandas en torno a la producción económica y reproducción social, definida a partir del modelo de desarrollo en cuestión, al que se responde partiendo de múltiples formas entre las que destaca la educación familiar (socialización primaria) con la consecuente inmersión en la ideología hegemónica y la incorporación al mercado de trabajo, garantizando con ello el cumplimiento de la generación de ingreso y participación en el consumo, muchas veces, a costa de su propio bienestar.

De forma relevante, estas presiones y mandatos se derivan también desde la política pública, particularmente la política social, demandando de manera permanente la toma de decisiones para responder a esas necesidades, lo que ocurre de forma particular y por tanto heterogénea, con diferencias generadas hasta cierto punto por su posición distinta en el engranaje social, atravesada por determinantes sociales como son la clase social, pero también el género del(a) jefe(a) de familia, etnia o raza a la que se pertenece, y ocupación, entre otras. Ello induce a la ampliación del abanico de formas y características en torno a los arreglos familiares, mismo que ha sido referido por la literatura especializada de manera consistente (De Riso, 2001; Arriagada, 2005 y 2007; Ariza y De Oliveira, 2001; Ribeiro, 2010; Ripol, 2001).

Lo anterior se manifiesta en la vida cotidiana, misma que da cuenta de relaciones, saberes particulares y compartidos, espacios y tiempos determinados, así como recursos y tareas. Si bien estos elementos, suelen considerarse desde la mirada tradicional como dinámica familiar, ello alude a aspectos fragmentados e independientes hasta cierto punto. Por el contrario, desde la perspectiva crítica, la vida cotidiana indica la imbricación de elementos particulares y hasta biográficos, en clara vinculación con aquellos aspectos de orden estructural, mismos que atraviesan de forma directa o indirecta a los mismos, como es posible observar en torno a la clase social, el género, la etnia, el contexto de residencia, entre otros. Es decir, la referencia a la vida cotidiana alude a la complejidad de la situación familiar y la manera en que la misma está situada en el contexto sociohistórico, económico, cultural y político. Por tanto, está claramente intrincada en el análisis de las transformaciones familiares.

Lo anterior coincide con lo señalado por Torrado (2002, retomado por Mallardi, 2018), quien alude a que la vida cotidiana está claramente vinculada con las estrategias familiares de vida, problematizadas a partir del análisis de 
las transformaciones familiares contemporáneas; de tal manera que dichas estrategias se observan en: el comportamiento de los agentes sociales de acuerdo con su posición social, la constitución y mantenimiento de las unidades familiares, así como en tareas realizadas para asegurar la reproducción biológica, preservar la vida y desarrollar aquellas prácticas económicas y no económicas necesarias para mantener las condiciones materiales y no materiales de existencia de la unidad familiar en general y de forma particular en sus miembros, es decir, en forma tanto individual como colectiva.

Adentrarse en el estudio de esas estrategias familiares como elementos cruciales para la comprensión de la vida cotidiana brinda la posibilidad de contar con categorías analíticas de base para la revisión de las transformaciones familiares, entre las que destacan: a) las estrategias de sobrevivencia, referidas a las acciones y tareas para lograr cubrir las necesidades materiales de cada uno de los miembros; b) las de existencia, constituidas por las tareas relacionadas con necesidades no materiales, destacando las afectivas y de comunicación; así como c) estrategias adaptativas dirigidas especialmente a brindar respuesta ante las múltiples tensiones externas (Torrado, 2002, retomado por Mallardi, 2018). Esto último, en particular, demanda al núcleo familiar la necesidad constante de tomar decisiones diversas como réplica ante las demandas continuas del contexto en que está inscrita; de tal forma, que ello constituye parte significativa de la heterogeneidad presente entre los diversos arreglos familiares, siendo mucho más que un cambio cultural y/o demográfico, una transformación situada en términos sociohistóricos.

Partiendo del planteamiento de Mallardi (2018) el presente análisis se centra en una revisión de las estrategias familiares que dan cuenta de la vida cotidiana, consideradas como categorías de análisis que de forma específica permiten retomar los diversos elementos en los que es posible tanto conceptualizar, así como operacionalizar el análisis de las transformaciones familiares. De esa manera y siguiendo a Mallardi (2018) el abanico de las estrategias/ categorías analíticas se amplía de forma evidente, quedando inscrito de la siguiente manera:

\section{Estrategias destinadas a la obtención de los recursos de subsistencia}

2. Estrategias vinculadas a la organización del cuidado

3. Estrategias habitacionales vinculadas a las condiciones de vida

4. Estrategias asociadas a los procesos de salud-enfermedad

5. Estrategias de socialización, aprendizaje y uso del tiempo libre

Las mismas serán abordadas, por tanto, como categorías de análisis en este documento y su operacionalización será realizada a partir de la revisión y reflexión en torno a algunas de las principales características y transformaciones observadas durante las últimas décadas en México, así como su relación con las políticas sociales implementadas y la manera en que ello se evidencia en la vida cotidiana de las familias.
2. Estrategias destinadas a la obtención de los recursos de subsistencia

En torno a este aspecto, es de suma relevancia señalar la creciente diversidad presente entre los arreglos familiares respecto a la manera en que se organizan para la obtención del ingreso necesario para cubrir las necesidades materiales del hogar. Los modelos observados en torno a ello se han diversificado en medida creciente, de tal forma que aquellos con un solo proveedor varón (por lo general, el padre de familia) permanecen, aunque disminuyen en proporción durante las últimas décadas, lo que suele estar vinculado por un lado, a la insuficiencia del salario, derivado en parte de la restricción salarial enfrentada por la clase trabajadora desde los ochenta, misma que se prolongó durante varias décadas tras surgir como parte de una estrategia política y económica dirigida a contener la creciente inflación de ese momento. De esa manera, la medida logró que por las siguientes décadas y hasta 2018 el salario mínimo mantuviese un imperceptible incremento anual, lo que tuvo un fuerte impacto en la situación financiera de las familias, representando a la larga una creciente distancia entre los costos concernientes a alimentos, servicios, vivienda y educación entre otros y, el ingreso obtenido por salario.

Derivado de lo anterior, los niveles de pobreza en la población se vieron incrementados durante las últimas décadas, generándose insuficiencia en el sostenimiento familiar, en especial al contar solamente con un salario o proveedor. Por tanto, y de la mano con el incremento promedio de los niveles de educación en las mujeres, aunado con un menor número promedio de hijos por mujer (al disminuir las tasas de fecundidad y natalidad) ${ }^{1}$, particularmente en las zonas urbanas, impulsó una transición al modelo de dos proveedores, mismo que se vio ampliado a finales de los años ochenta y en especial en las siguientes décadas, con el ingreso creciente de mujeres (particularmente unidas y con hijos) ${ }^{2}$ al mercado laboral. A lo anterior, se agrega otro modelo, que no puede indicarse de surgimiento reciente, pero sí de una tendencia distinta, especialmente durante las últimas décadas; referido al modelo de proveedora mujer solamente, creciendo fuertemente en proporción, en especial a partir del incremento, por un lado, de rupturas conyugales (separaciones y divorcios), así como por el aumento proporcional de la maternidad en solitario presente en un mayor número de mujeres. Además, tenemos que considerar otras situaciones como es la presencia de un mayor número de proveedores por hogar, lo que sue-

\footnotetext{
${ }^{1}$ La literatura especializada (Ariza y De Oliveira, 2004. Zavala, 2014) suele explicar que la relación entre la disminución del número promedio de hijos por mujer y el incremento de la escolaridad media entre las mujeres, es producto tanto de la política educativa, misma que brindó mayores posibilidades de ingreso a las mujeres a la educación pública, paralelo a una fuerte política poblacional que buscó disminuir el crecimiento de población, a través de la generalización del uso de métodos anticonceptivos y la incorporación de educación sexual temprana dirigida a incidir en ello, entre otras cosas. Ambas políticas repuntaron durante las últimas décadas del siglo pasado.

2 Las mujeres solteras ya se habían ido incorporando al mercado laboral con anterioridad a ese momento.
} 
Gráfico 1. Porcentaje de hogares con jefatura femenina y masculina con respecto al total de hogares

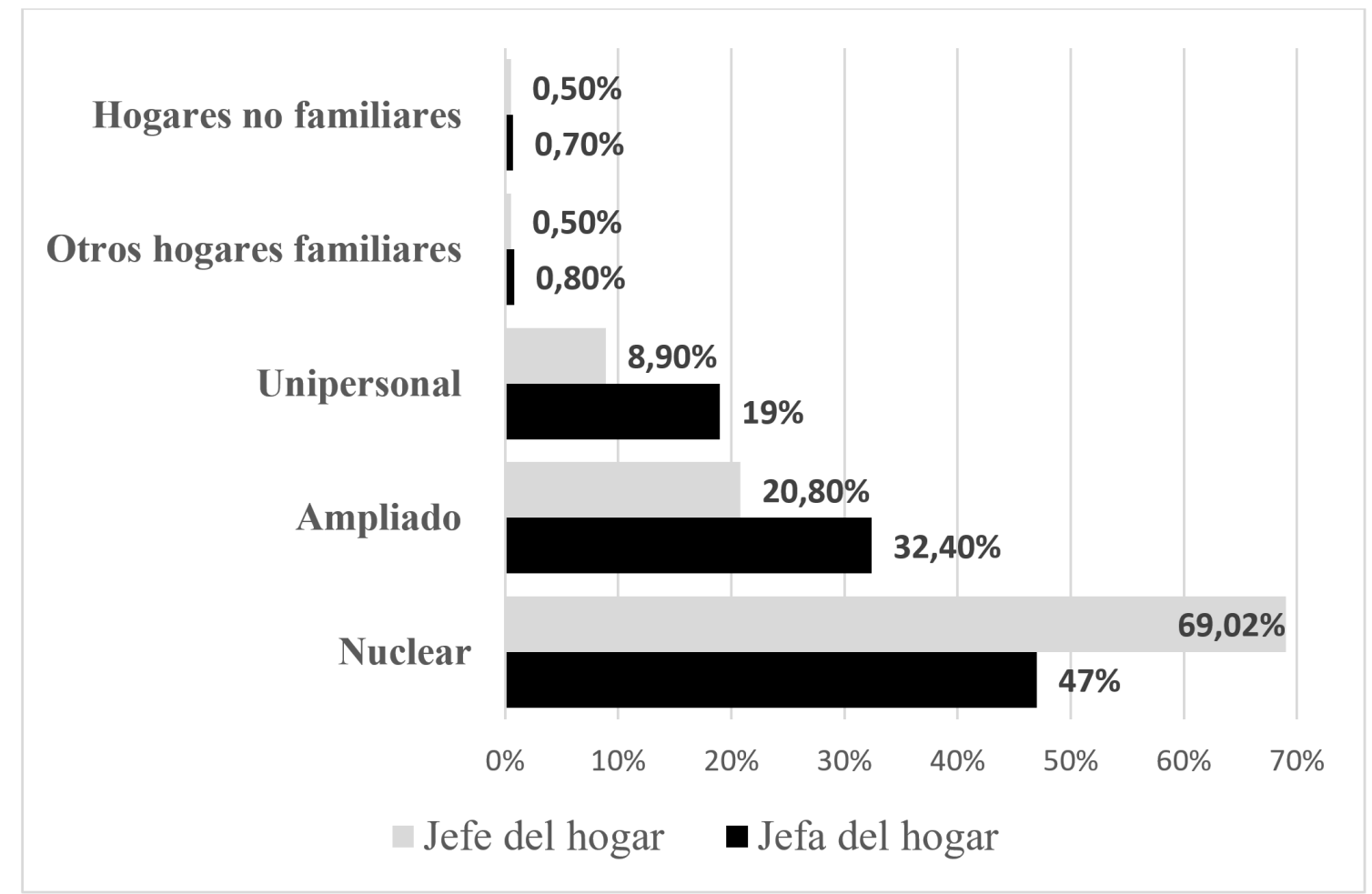

Fuente: INEGI (2018), Encuesta Nacional de la Dinámica demográfica.

le estar vinculado con los elevados niveles de pobreza en la población, haciendo necesario que también hijos(as) u otros(otras) miembros del hogar se incorporen al mercado de trabajo y aporten al gasto familiar, de tal forma que ello permita cubrir las necesidades materiales de sus miembros. Lo anterior se hace patente en la Tabla 1.

Tabla 1. Mujeres y hombres que tuvieron su primer empleo en México por cohorte y tamaño de localidad

\begin{tabular}{|c|c|c|c|c|}
\hline $\begin{array}{c}\text { Porcentaje de quienes } \\
\text { tuvieron su primer } \\
\text { empleo en primeros } \\
20 \text { años }\end{array}$ & \multicolumn{2}{|c|}{$\begin{array}{c}\text { Localidades de } \\
\text { menos de } 2500 \\
\text { habitantes }\end{array}$} & \multicolumn{2}{|c|}{$\begin{array}{c}\text { Localidades de } \\
2500 \text { y más habi- } \\
\text { tantes }\end{array}$} \\
\cline { 2 - 5 } & Mujeres & Hombres & Mujeres & Hombres \\
\hline $1962-1967$ & 47,7 & 88,5 & 60,8 & 78,9 \\
\hline $1968-1977$ & 53,8 & 86,2 & 56,3 & 79,0 \\
\hline $1978-1987$ & 52,3 & 84,1 & 58,4 & 74,9 \\
\hline $1988-1997$ & 50,3 & 82,5 & 50,4 & 68,2 \\
\hline
\end{tabular}

Fuente: INEGI (2018) Encuesta Demográfica Retrospectiva (EDER) 2017. Tabulados básicos.

No obstante, la transición en gran proporción de las familias con modelo de único proveedor varón al modelo de varios proveedores, o de proveedora mujer solamente, no se deriva solamente de las políticas salariales impuestas en México a partir de los años ochenta, sino que ello se imbrica con políticas laborales que conllevan a una creciente flexibilización y precarización laboral, evidente tanto en los mayores niveles de explotación a los trabajadores, el cambio en sus condiciones de trabajo, entre las que sobresalen la temporalidad de los contratos, el que sean realizados a través de terceros, menores niveles de protección y de seguridad social, entre otras. Lo anterior, aparece como parte de las políticas económicas y sociales de corte neoliberal, impulsadas por el gobierno en turno durante el período señalado, mismas que fueron fuertemente recrudecidas en las siguientes décadas, con una tendencia marcada hacia el crecimiento económico y la generación de riqueza, aún sobre el sacrificio del bienestar de la población. Ello conformó parte del replanteo de los modelos de desarrollo económico en el país, que buscaron acatar las medidas establecidas por los organismos internacionales para lograr el crecimiento económico esperado.

Lo señalado ha derivado en múltiples y crecientes tensiones al interior del hogar, en donde además de la creciente incertidumbre enfrentada, especialmente en torno a la subsistencia; aspectos como la dependencia versus autonomía de algunos miembros genera ambivalencias, tensiones y conflictos diversos. De esa manera, en el primer modelo predomina la dependencia de la madre y los hijos con respecto al padre (único proveedor), estableciéndose a la primera al frente del poder doméstico que la conmina a cumplir con las responsabilidades y tareas domésticas, 


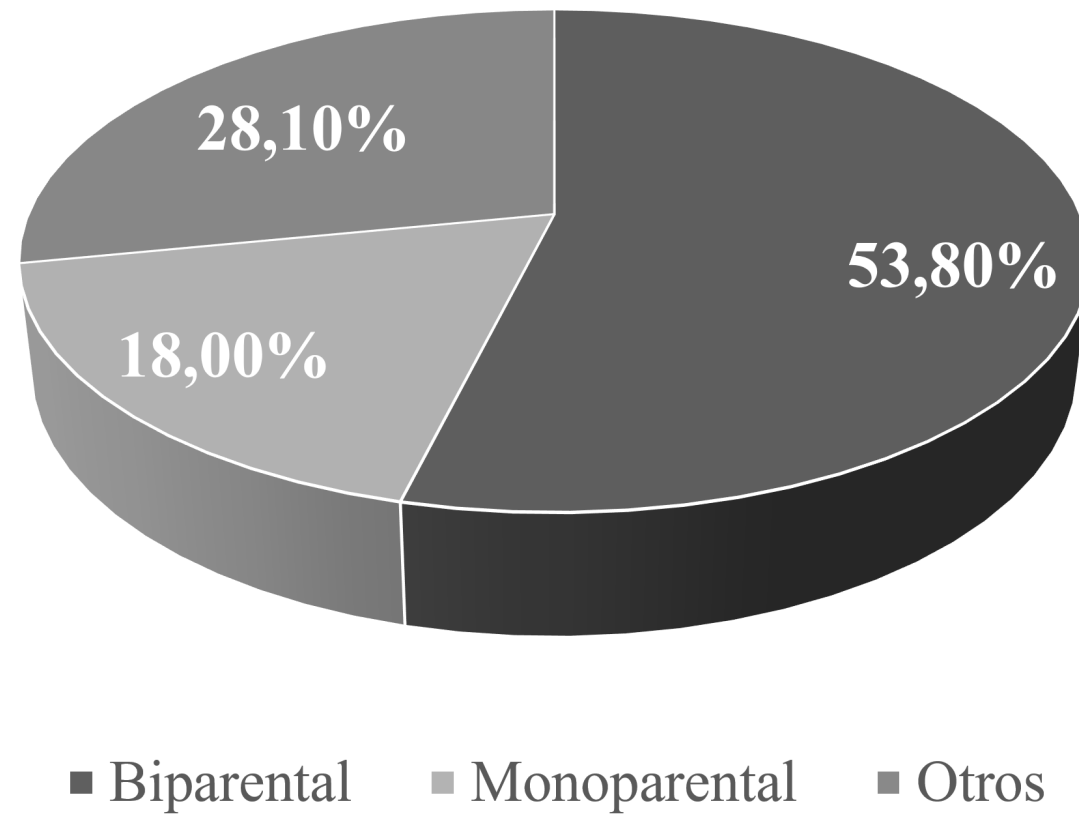

Fuente: INEGI (2017), Encuesta Nacional de los Hogares.

así como especialmente las de cuidado (Mallardi, 2019). Este modelo tradicional sigue vigente en México, a pesar de las dificultades que ello conlleva para el sostenimiento económico de la familia; si bien no es visible la medición de hogares con un solo proveedor varón, esto se evidencia en torno a la jefatura del hogar, siendo principalmente masculina como puede observarse en los datos oficiales del Instituto Nacional de Estadística y Geografía en México (2018) (véase Gráfico 1).

Como es posible observar, en los hogares familiares de tipo nuclear predomina la jefatura masculina, lo que indica la prevalencia de hogares en los que el varón sigue siendo el proveedor principal, en muchos casos, el único. Ello se confirma en el hecho de que las estadísticas oficiales refieren que la participación de las mujeres en el mercado laboral presenta una correlación negativa con su edad y el número de hijos que tiene, puesto que la mitad $(49,6 \%)$ de aquellas con 15 o más años de edad que tiene entre uno a dos hijas(os) está incorporada al mercado de trabajo, siendo menor $(41,4 \%)$ en el caso de quienes tienen entre tres a cinco hijas(os), mientras que solamente una de cada cinco $(22,7 \%)$ está constituido por aquellas que lo hacen teniendo entre seis o más hijas(os) (INMUJERES, 2018). Otro aspecto asociado a ello es el estado conyugal de las mujeres, puesto que las mujeres unidas o casadas realizan actividades remuneradas, por lo general de manera extra doméstica en $39 \%$, es decir en cuatro de cada diez casos, a diferencia de quienes son madres en solitario (69\%) y aquellas cuyo estado civil es separada, divorciada o viuda (46\%) de acuerdo con las cifras estadísticas oficiales en el 2017 (INMUJERES, 2018).
El segundo modelo, considerado como "de doble ingreso" disminuye ese tipo de dependencia, generándose posibilidades de "autonomía relativa", que no se logra en su totalidad, puesto que esa transición implica la transgresión a mandatos fuertemente arraigados, la incorporación de la mujer al mercado laboral se legitima de forma condicionada, solo si no descuida o abandona su principal tarea "el cuidado de los miembros dependientes" (Mallardi, 2018). Por tanto, el ingreso de la mujer o madre queda circunscrito a ser complementario, circunstancial y transitorio, en tanto se considera que la misma, solamente ayuda al varón o padre a cumplir con sus responsabilidades de sustento al hogar, mientras que ella asume la responsabilidad por las tareas de cuidado y atención al hogar. Es decir, suele persistir una rígida división del trabajo y especialización de tareas al interior del hogar, en función del género, dejando escasas posibilidades a la corresponsabilidad entre los miembros.

Es necesario resaltar que quienes son madres realizan su inserción al mercado de trabajo en situaciones de mayor precariedad y además con cada vez mayor sobrecarga, teniendo que atender a la par su actividad remunerada y el cuidado de las(os) hijas(os): es así que $40,9 \%$ de las mujeres cuya edad fluctúa entre los 25 y 49 años y que tienen hijas(os) menores de 3 años participa en el mercado laboral, mientras que entre aquellas que no las(os) tiene(n) su incorporación corresponde a 68,2%; dicha situación no presenta diferencias significativas entre los varones, es decir, entre estos el tener o no hijos(as) no es un aspecto que influya en su situación laboral. Otro aspecto que resalta en términos de la situación laboral precaria para las primeras 
es el hecho de que $80,6 \%$ de las mujeres con hijas(os) no tiene acceso al servicio de guardería para su cuidado (INMUJERES, 2015; CEPAL, 2016). Lo último deja entrever que la política social sigue teniendo una tendencia familiarista, en la que se apuesta al recurso familiar para resolver las necesidades de sus miembros, lo cual cuando falla, se considera que se acudirá al mercado para resolverlas a través del consumo especializado, siendo aún mínima la respuesta a ello de parte de la acción pública, además que el actual gobierno redujo aún más dicha política en el caso mexicano.

El tercer modelo, surge en muchos casos, tras el resquebrajamiento o ruptura conyugal, considerándose la opción principal ante aquellas situaciones consideradas como "fallas" como son las separaciones y divorcios, aunados a la maternidad en solitario. Es considerado como un modelo que, si bien parece dar cuenta de que la mujer goza de mayor autonomía, especialmente en torno a la toma de decisiones, así como la organización y acceso a los recursos, también constituye una transgresión a mandatos arraigados en la sociedad, motivo por el que suele ser estigmatizada, particularmente el que señala al varón o padre como principal proveedor y/o jefe de familia (Tamez y Zúñiga, 2016). Otro aspecto de este modelo es su clara vinculación con la maternidad, la cual es más evidente en el caso de aquellas consideradas como madres solteras, mismas que en $69 \%$ se encuentran incorporadas al mercado laboral, mientras que quienes presentan una situación conyugal de estar separadas, divorciadas o en viudez constituye el $46 \%$, a diferencia de las unidas o casadas, en las que como ya fue señalado solamente cuatro de cada diez participa en el mercado de trabajo (INMUJERES, 2018).

Desde la mirada de la política social, este modelo constituye una de las principales estrategias para resolver la pobreza, particularmente la identificada en las familias monoparentales; en tanto la incorporación al mercado de trabajo de las mujeres madres al frente de un hogar suele estar asociada con la necesidad de sobrevivencia de los miembros de esos hogares. Eso no quiere decir que sea posible generalizar las características de la monoparentalidad femenina y considerar a la misma de manera homogénea, en tanto ya fue señalado por la literatura y diversos estudios previos la situación de gran heterogeneidad entre los mismos (Mendoza, 2016; Poxtan, 2010; Tamez y Zúñiga, 2016). Lo anterior, no omite el análisis de la exclusión enfrentada por las mujeres al incorporarse al mercado laboral, misma que se presenta tanto en términos de salario, así como de puesto (techo de cristal), ocupación e incluso de sector productivo, siendo excluidas en mayor medida que los varones por el sector industrial (García y De Oliveira, 2004; Rendón, 2008).

A lo anterior también habrá que agregar la situación generalizada de flexibilización y precarización laboral observada en el mercado de trabajo durante las últimas décadas, presente principalmente en el caso de las mujeres, especialmente en una mayor informalidad del trabajo, trayectorias intermitentes y fluctuantes, jornadas muy diversas $y$, por tanto, menor acceso a protección social y a pensiones por jubilación. Si además se considera que las mujeres, especialmente aquellas que son madres, tienen trayectorias interrumpidas en sus empleos y que por las múltiples tareas que realizan muestran traslados continuos $y$, en ocasiones prolongados, a partir de las demandas que enfrentan a lo largo del ciclo de vida familiar, su vulnerabilidad en el mercado laboral se ve incrementada.

En el último año y asociado con la crisis sanitaria por COVID-19 enfrentada a nivel mundial, la Comisión Económica para América Latina ha señalado que en la región se están recrudeciendo las brechas entre los grupos sociales, particularmente las de género, evidentes principalmente en la situación económica, puesto que se observa un aumento de la pobreza y una feminización de la misma, al encontrarse sobrerrepresentadas las mujeres en los hogares con situación de pobreza; la proporción de mujeres desempleadas ha crecido en mayor medida que la de los varones; ellas también se concentran en el trabajo informal y pequeñas empresas, así como en sectores con mayores riesgos de contracción; también se encuentran en mayor medida que los varones en sectores de baja calificación enfrentando mayores riesgos de pérdida de empleo; asimismo, ocupan puestos en la primera línea de atención de la pandemia en mayor proporción que los varones; estas enfrentan un aumento de la demanda de cuidados al interior del hogar; a ello se agrega una recrudecida brecha respecto al uso digital de información y aplicaciones en dispositivos electrónicos (CEPAL, 2021; INEGI, 2020). Todo ello da cuenta del ensanchamiento de las desigualdades preexistentes a la pandemia actual, mismas que se han visto profundizadas, repercutiendo ello especialmente en las mujeres, quienes además de verse impactadas en sus condiciones materiales, también enfrentan mayores demandas de cuidado que implican sobrecarga, desgaste y un incremento en los niveles de estrés.

Si se retoman los cambios observados recientemente, ocurridos durante y a partir de la situación de crisis sanitaria por COVID-19, en donde se advierte que el trabajo ha adquirido nuevas formas, al realizarse principalmente a la distancia, por lo general desde el hogar, a través de la tecnología y sus aplicaciones; tendremos que resaltar de inicio el que los tiempos y horarios se han difuminado, perdiéndose límites entre las tareas y los espacios de trabajo productivo y reproductivo, transformando casi en su totalidad las rutinas y los procesos vinculados a ambos tipos de trabajo; asimismo, se advierte una mayor sobrecarga de trabajo, especialmente para las mujeres, quienes realizan en mayor medida multitareas. De manera paralela y en total vinculación con lo anterior, se advierten nuevas formas de explotación laboral, evidentes en particular en las formas renovadas de vigilancia, así como de control y hasta disciplinamiento de los trabajadores; al facilitarse el seguimiento de sus actividades y partiendo de la idea que como se trabaja en casa, no se tienen restricciones de horario.

La revisión realizada en torno a las transformaciones familiares observadas respecto a las estrategias destinadas a la obtención de recursos de subsistencia no es exhaustiva como se puede ver, sin embargo, presenta un panorama de la situación enfrentada durante las últimas décadas. Asimismo, dicha revisión permite dar cuenta de las numerosas y crecientes tensiones enfrentadas de manera diferenciada por los diversos arreglos familiares, recrudeciéndose en algunos de los casos, en especial en aquellos con un solo proveedor, particularmente cuando el mismo es una madre con hijos dependientes; los cuales muestran 
una tendencia creciente durante los últimos años como es posible observarlo en el Gráfico 2. También se evidencia en lo reportado por CEPAL (2016): la distribución del ingreso presenta cada vez mayor desigualdad, originada en la década de los ochenta, misma que creció de manera vertiginosa hasta el 2000 y posteriormente siguió exacerbándose hasta la actualidad, pero en menor grado; por ello América Latina es considerada una de las regiones con mayor desigualdad en el mundo, aun cuando no sea la de mayor pobreza.

Las tensiones y ambivalencias a las que se alude suelen derivarse de las contradicciones enfrentadas por las determinantes sociales (género, clase, etnia, ocupación, contexto de residencia, edad, entre otras) y producto de la dirección marcada por las políticas sociales del país, mismas que en el caso de México definen la responsabilidad de la situación en el entorno familiar, en espera de que la toma de decisiones y agencia de los miembros, especialmente del(a) jefe(a) de familia sea acorde a la respuesta de las necesidades del hogar. A partir de ello, se espera como resultado el acceso y distribución de los recursos entre los miembros, tanto los materiales, como los de tiempo; mismos que de no ser posible cubrirlos con sus propios recursos sea posible recurrir al mercado, en tanto la respuesta estatal se reduce a sus formas mínimas. No obstante, cabe señalar que, a partir del inicio del actual sexenio presidencial, se buscó atender y echar atrás la recesión salarial establecida desde el siglo pasado, lo que permitió por fin un aumento del salario mínimo más acorde con los niveles de inflación observados ${ }^{3}$. Aunque ello no ha impactado de forma relevante el poder adquisitivo de la población, al encontrarse mermado por los niveles de inflación presentes en el país y recientemente, tras el impacto económico y social de la pandemia por COVID-19.

\section{Estrategias vinculadas a la organización del cuidado}

Esta categoría de análisis permite retomar un punto crucial de la vida cotidiana, el cual refiere a una tarea esencial para los miembros del hogar, misma que tiende a ser invisibilizada desde la política social, especialmente bajo un régimen familiarista, dándose por hecho que le corresponde de manera exclusiva a la familia la respuesta y atención de las necesidades de cuidado de aquellos miembros considerados como dependientes.

\footnotetext{
3 El salario mínimo fue poco significativo durante décadas en México, llevando a una caída constante del poder adquisitivo de los trabajadores, de tal manera que el primero se movió entre el $2 \%$ y $4 \%$ entre 1986 y 2017, evidenciándose en los montos de 14,27 en 1992 que subió a 43,65 en diez años (2002) y 62,33 al 2012, veinte años después. Es a partir de 2017 se han realizado intentos por mejorar dicho poder adquisitivo, subiendo el salario mínimo diario un 9,58 \%, $10,38 \%$ en $2018,16,21 \%$ al 2019 y $20 \%$ al 2020 ; claro que estos aumentos han tenido una merma en función del nivel de inflación presente; que además en el momento actual tiene mayores repercusiones debido a la situación de pandemia enfrentada. El salario mínimo al 2019 correspondía a 102,68 y 123,22 al 2020 (Banxico, INEGI y STPS, 2020).
}

Desde la visión de Rodríguez Enriquez y Pautassi, (2014 retomados por Mallardi, 2018) el cuidado es concebido a partir del conjunto de actividades destinadas a atender las necesidades de personas dependientes ya sea por su edad, o por sus condiciones o capacidades, siendo consideradas como actividades indispensables para satisfacer las necesidades básicas de la existencia y reproducción de las personas, al brindarles elementos físicos y simbólicos.

Esas actividades y tareas incluyen tanto actividades directas de cuidado de otros, particularmente de los miembros dependientes, así como actividades indirectas como son las que incluyen limpieza del hogar, lavado de ropa, preparación de alimentos, compra de víveres y medicamentos, acompañamiento y escucha, entre otras. Asimismo, se consideran aquellas relacionadas con la gestión del cuidado, como búsqueda y contratación de cuidadores, pago a los mismos y la procura de condiciones para el cuidado. Por tanto, presenta muchas aristas para su análisis, así como su vinculación con la política social.

El cuidado ha sido considerado una acción que corresponde al ámbito privado, ubicándose al mismo en el entorno familiar, principalmente de las mujeres. Por tanto, constituye un punto crucial del proceso de familiarización, particularmente maternalización de la política social, mismas que refuerzan roles y prácticas tradicionales (Mallardi, 2019). Al ubicarse el cuidado como parte de las tareas domésticas marcadas por el género y exclusivamente femeninas, en las que el varón simplemente apoya o ayuda, se omite su responsabilidad y/o corresponsabilidad en la atención de las necesidades de cuidado a miembros dependientes.

Esa misma omisión se presenta por parte del Estado, en tanto responsable de proveer los medios para que el cuidado pueda ser brindado, particularmente las condiciones para que el mismo se brinde sin discriminación, en igualdad y como un derecho social. De ahí la necesidad de analizar esta situación desde la economía del cuidado y como una cuestión de derechos, desde una visión de ciudanía. Contrario a ello, resalta la desigualdad presente en la organización cotidiana del cuidado, así como la ausencia del Estado en términos de su intervención social para garantizar este derecho de manera no mercantilizada, sino a partir de la política pública y social.

Esa omisión ocurre a través de la separación entre el mundo público signado por la producción de capitales y el mundo privado, reservado al trabajo reproductivo; ello vinculado con la construcción social, patriarcal y hegemónica de la sociedad, en la que las mujeres son segregadas y excluidas en el mercado de trabajo por tener asignado ese mandato moral y social "de cuidar de otros" de ser "un cuerpo para otros" como ha sido señalado por Lagarde (1993). Ello recrudece la desigualdad entre los géneros, que lleva a que las mujeres utilicen un mayor número de horas en tareas domésticas y de cuidado que los varones, aun cuando ambos tengan hijos u otros miembros de la familia que cuidar y/o atender.

La separación del trabajo productivo y reproductivo constituye parte de los procesos de reproducción social que conllevan a la reproducción de la fuerza de trabajo en la sociedad capitalista, de tal manera que ello permite garantizar la fuerza de trabajo para la producción y repro- 
ducción tanto del capital, como de las relaciones sociales (Guerra, 2017). Por tanto, la familia es utilizada para sufragar costos de dicha reproducción y, además asegurar el disciplinamiento de las personas a partir de la ideología hegemónica (neoliberal y patriarcal). Ello se hace patente cuando a pesar del ingreso generalizado de las mujeres al mercado laboral, las responsabilidades domésticas y de cuidado no se ven alteradas, sino por el contrario, siguen estando asignadas a las mujeres, independientemente de su participación en el trabajo extradoméstico o productivo y la carga de trabajo que ello implique (Mallardi, 2018). Lo anterior conlleva a una creciente sobrecarga concerniente a una triple jornada laboral que tiene fuertes repercusiones tanto en los niveles de autonomía de las mujeres, así como en sus niveles de tensión, estrés $y$, por tanto, en su desgaste físico y mental.

Lo anterior constituye la marca de la política social en México, que al igual que en la región de Latinoamérica, se encuentra familiarizada, en tanto se le apuesta o incluso da por hecho que es la familia la instancia que está y estará ahí para responsabilizarse del bienestar de sus miembros, en especial cuando éstos requieren de cuidados por su condición de edad y/o de dependencia, ya sea por su desarrollo, enfermedad, discapacidad o vejez. Además de ubicar la responsabilidad en la familia, la política social en México tiene un sello de maternalización de la misma, sobrevalorando el hecho de ser madre, pero además centrando en sus manos la atención y respuesta al cuidado, tarea que se considera exclusiva de la mujer. Asimismo, y con el aporte del patriarcado, se impulsa al maternaje, en tanto las mujeres, aun cuando no sean la madre, ejercen funciones y tareas equivalentes, cuidando, por tanto, no solamente a hijos(as), sino también a otros(as) parientes, incluso a la propia pareja, o bien a padres, abuelos y a veces hermanos(as), especialmente al cohabitar con ellos(as) (Lamas, 1996; Tamez, 2008).

El papel del Estado tendría que ir en vías de mayor corresponsabilidad, actuando como garante del derecho al cuidado, además de brindar las condiciones necesarias para que el mismo se lleve a cabo. Ello implica un enfoque centrado en derechos, que desde una visión de ciudadanía regule toda acción institucional dirigida de manera directa o indirecta a las familias y sus necesidades de cuidado. El tema de cuidado, por tanto, tendría que ser central en la agenda pública, vinculándose con los programas económicos y sociales, particularmente con la política laboral y los programas de intervención que abordan a los grupos familiares.

Gran parte de la literatura especializada (Lamas, 1996; Lagarde, 1993; Ariza y De Oliveira, 2004; García y De Oliveira, 2004) subraya la desigualdad por género, evidente en torno a la organización del cuidado, misma que reproduce los roles tradicionales de hombres y mujeres respecto al mismo. También los datos oficiales brindados por los diversos estudios y análisis realizados en torno al tiempo que señalan la inversión realizada en promedio por hombres y mujeres tanto en el trabajo productivo, como en el reproductivo, así como las brechas presentes entre los mismos (Rendón, 2008).

Algunos de los efectos derivados de esta marcada desigualdad en función del género serán revisados en el punto referente a estrategias en torno a la salud, no obstante, también se evidencian impactos sociales como es la feminización de la pobreza, sin que ello signifique que solamente las mujeres enfrentan situaciones de precariedad y carencias, pero sí que los recursos en ellas son más limitados, referido esto no solamente a los recursos materiales o económicos, sino en particular los de tiempo. Dicha feminización de la pobreza alude hasta cierto punto a la manera en que la sobrecarga de trabajo femenino le impide realizar el autocuidado en términos de su propio bienestar, llevando a un mayor deterioro en dicho grupo, así como el incremento de tensiones, conflictos y por supuesto mayores niveles de estrés entre las mismas.

Un aspecto de particular importancia, refiere a la creación de redes de apoyo, las cuales constituyen en muchos casos, especialmente entre aquellas que por razones de precariedad y exclusión requieren ayuda de terceros, la principal estrategia de apoyo para garantizar su sobrevivencia. No obstante, su creación y fortalecimiento son elementos que demandan una gran inversión de tiempo, recurso que se encuentra comprometido por lo previamente señalado. Lo anterior es particularmente relevante durante la vejez, lo que implica una seria limitante no solo para el presente de las mujeres en su edad productiva, sino de manera especial en el futuro, cuando además requerirán en mayor medida de la respuesta de esas redes, tanto de pares, como intergeneracionales (Arroyo, 2009; Tamez y Zúñiga, 2016; Tamez, 2020). Por tanto, el impacto de la sobrecarga enfrentada particularmente por las mujeres no solamente es notorio en el corto y mediano plazo, sino también se torna significativo al llegar a la vejez, momento en que además suelen recrudecerse todas las formas de desigualdad y de exclusión social enfrentadas durante la trayectoria de vida, pero en la cual además suelen invertirse los papeles en torno al cuidado y la necesidad de recibirlo por desarrollo de dependencia.

4. Estrategias habitacionales vinculadas a las condiciones de vida

La vivienda es uno de los elementos más relevantes desde la política social, particularmente desde el ámbito de la salud, tanto física como mental, y de forma particular desde la acción del Trabajo Social. De esa manera, ha sido reportado en la literatura la manera en que el papel de visitadora fue uno de los principales a desarrollarse en el área de salud, particularmente desde los primeros ejercicios de salud social, aun cuando en algunos contextos y especialmente al principio adquirió tintes de inspección para asegurar la higiene de los espacios utilizados por los pacientes y sus familias como prolongación del hospital y del consultorio médico (Cabot, 2008). De tal manera que ha sido considerada una extensión del espacio de tratamiento y atención, mismo que por tanto deberá ser debidamente vigilado y supervisado por los profesionales de la salud, 
especialmente aquellos que representan la extensión del médico hacia el hogar, sitio privilegiado y asumido principalmente por el Trabajo Social.

De esa manera, la vivienda es visitada para constatar que presenta cualidades suficientes en términos de higiene y profilaxis para el tratamiento y/o recuperación del paciente, o bien, en términos de la prevención requerida por algunos padecimientos infecciosos (Cabot, 2008). En términos de salud mental, constituye un espacio que da cuenta de elementos considerados básicos para lograr este aspecto entre los miembros de la familia, vigilándose que el hogar no presente características que conlleven al hacinamiento $\mathrm{y} / \mathrm{o}$ promiscuidad, considerados como factores de riesgo y/o aspectos que detonan padecimientos mentales entre los miembros del hogar.

Otros elementos que han sido ampliamente estudiados de la vivienda corresponden al tipo y calidad de los materiales utilizados, así, por ejemplo, que el piso sea de tierra es un elemento considerado de precariedad y pobreza, además de pernicioso, aislándose ello del contexto en el que se presenta, puesto que en zonas rurales, especialmente de lugares con clima extremoso, constituye un elemento térmico que permite mantener la temperatura del interior ante la adversidad climática. Lo mismo ocurre con los techos de palma y las paredes de adobe, entre otros, mismos que poco a poco se extinguen, pese a sus características benévolas ante el clima adverso y las necesidades sociales de las familias de mantener los interiores templados. De hecho, el clima de algunas regiones es un elemento crucial para la salud que suele omitirse al momento de diseñar y construir viviendas, particularmente aquellas de "interés social" y en zonas urbanas o periféricas, diseñadas para ser habitadas por los(as) trabajadores(as) y sus familias.

Lo anterior, omite la consideración que en la mayoría de los casos, la propia política de vivienda impacta este tipo de situaciones, en tanto el tamaño de la vivienda, en particular de sus habitaciones, así como el diseño propio de la misma, sus características y hasta la ubicación, no son acordes ni adecuados para cubrir las necesidades sociales de la familia, sino por el contrario, definidos y diseñados, así como construidos en función del mercado, priorizando el valor de cambio en la toma de decisiones, y omitiéndose el valor de uso, vinculado con la funcionalidad del hogar y la cobertura de las necesidades sociales de los miembros del grupo familiar.

La vivienda como eje de análisis, señala Mallardi (2018) se encuentra vinculada a las condiciones de vida de las personas, dando cuenta por un lado de las prácticas de cohabitación, tanto en términos cuantitativos como es el número de habitantes promedio por hogar, así como cualitativos, referentes a vínculos entre los miembros del hogar evidentes en el tipo de arreglo familiar que predomina, así como a las actividades individuales, familiares y sociales de los mismos. Pero en términos más estructurales, da cuenta de las situaciones de precariedad enfrentadas por dichos grupos, entre ellas la segregación espacial de pobreza en términos de lo previamente señalado, la ubicación, el tamaño y los espacios disponibles dentro de la misma; particularmente la medida en que son acordes o no a las necesidades sociales de la familia, sobre todo en términos de su organización de actividades como son la organización del cuidado y los procesos de salud-enfermedad.

Por otro lado, el análisis de la vivienda en tanto evidencia las condiciones de vida familiar, deja entrever la desigualdad presente entre las familias, al visibilizar la apropiación desigual de los recursos en el tipo y características de la vivienda que habitan, particularmente su ubicación, tamaño, materiales de construcción, especialmente acabados o recubrimientos y servicios. De hecho, el acceso a los bienes y particularmente a los servicios es un elemento crucial en términos de la evaluación de carencias sociales en estos grupos, permitiendo dar cuenta de su situación en términos de pobreza multidimensional.

Un aspecto relevante de la vivienda y su análisis estriba en el sentido de la misma como soporte del hogar, al brindar de elementos que en términos ideales se espera que logren cubrir las necesidades sociales de la familia. Sin embargo, al igual que en otros elementos, esto suele definirse desde otro ámbito, relacionado con la disponibilidad de recursos que tienen las familias, particularmente los de tipo financiero, predominando por tanto el valor de cambio y aspectos como la plusvalía, por sobre el valor de uso y por tanto, la utilidad y funcionalidad de la vivienda, de tal manera que la misma permita atender las crecientes necesidades de sus miembros, en especial conforme avanza el ciclo de vida (llegada y crecimiento de los hijos, incorporación de personas mayores en el hogar, entre otras).

Tampoco se considera la heterogeneidad presente entre los arreglos familiares, así como sus prácticas cotidianas y demás aspectos vinculados con la cultura, recreación, descanso, entre otros. En gran parte de las construcciones, particularmente en las urbanas, al momento de diseñar y construir viviendas de interés social se omite el tema de servicios disponibles, a excepción de los básicos, así como de instituciones de salud, educativas, e incluso el servicio público de transporte. Esto en gran parte, porque suelen construirse en zonas periféricas a las grandes urbes, al carecer de un diseño urbano las mismas y en la búsqueda por disminuir los costos para los inversionistas en bienes raíces. Lo anterior suele tener un alto impacto para las familias, puesto que generalmente y en el mejor de los casos, el servicio de transporte suele ser gestionado de manera posterior a la llegada de los grupos familiares a morar en su vivienda y en función de la demanda creciente; por tanto, ello tiene un alto impacto económico para las familias durante el periodo inicial de su residencia, al tener que desembolsar mayores cantidades para pagar por su traslado por estar etiquetado como regional, no como un servicio local de transporte público.

Lo señalado, da cuenta de las tendencias observadas en México respecto a la formación socioespacial de las ciudades, especialmente en los contextos urbanos, las cuales son resultado del conflicto y apropiación tanto del espacio, como de los recursos que son producidos socialmente, pero cuya distribución, ocurre bajo la lógica de la concentración de dichos recursos a partir de luchas de poder al interior de la sociedad (Mallardi, 2018). Ello determina las diversas condiciones de vida en la población, quedando algunos grupos segregados socialmente y con servicios de menor calidad, o bien enfrentando carencias y/o limitantes que reflejan en algunos casos, una clara exclusión social y 
Tabla 2. Incremento de la esperanza de vida al nacer en México

\begin{tabular}{|l|c|c|c|c|c|c|c|c|c|c|c|c|}
\hline Año & 1950 & 1955 & 1960 & 1965 & 1970 & 1975 & 1980 & 1985 & 1990 & 1995 & 2000 & 2005 \\
\hline Nacional & 49,6 & 56,1 & 59,2 & 61,2 & 63,1 & 65,7 & 68,4 & 70,6 & 72,6 & 73,6 & 74,0 & 74,6 \\
\hline Hombres & 48,1 & 54,5 & 57,6 & 59,4 & 60,9 & 62,1 & 65,5 & 67,9 & 70,2 & 71,3 & 71,6 & 72,2 \\
\hline Mujeres & 51,0 & 57,7 & 60,8 & 62,1 & 65,3 & 68,5 & 71,3 & 73,3 & 75,1 & 75,1 & 76,5 & 77,0 \\
\hline
\end{tabular}

Fuente: Benítez y Cabrera, 1967; Gómez de León y Partida, 1998; INEGI 2005.

espacial; mientras que los grupos con mejor posición social y política se ubican en espacios privilegiados y acceden a servicios de mejor calidad en dichas urbes.

De esa manera, tanto la apropiación desigual del espacio urbano, así como el acceso a los servicios públicos en general, y en lo particular al tipo, tamaño y materiales de la vivienda, se encuentran claramente asociados con aquellas necesidades derivadas del mantenimiento y la reproducción de la fuerza de trabajo (Mallardi, 2018). Por tanto, su análisis debe estar definido a partir de las determinaciones sociohistóricas, entre las que destacan las de clase social, así como el origen étnico, género y generacionales, entre otras.

Si además de lo anterior, se considera la omisión, en gran parte de las ciudades del país, no solo de un diseño urbano que permita considerar los elementos señalados, sino además los trayectos que trabajadores(as) y sus dependientes tendrán que realizar para trasladarse de su casa a sus empleos, escuelas y demás instituciones sociales y económicas; situación que contribuye aún más a tensionar la vida cotidiana de las familias, particularmente las relaciones y convivencia entre sus miembros.

Cabe señalar que la segregación espacial y situaciones de precariedad que enfrentan un gran número de familias, aunadas a un deficiente o limitado acceso a los servicios públicos tiene serias implicaciones en las condiciones de vida de la población, afectando sus recursos de tiempo, mermados por los grandes trayectos que recorren y los tiempos invertidos en ello, mismos que se agregan a mayores costes de recursos materiales y no materiales. La conjunción de dichos elementos tiene impacto tanto en la organización de tareas y distribución de recursos al interior de la familia, así como en las posibilidades de convivencia. Por tanto, el impacto que lo anterior tiene en la vida cotidiana de las familias, repercute tanto de manera directa como indirecta en las condiciones de salud de sus miembros, como se revisa en el siguiente apartado.

5. Estrategias asociadas a los procesos de salud-enfermedad

Las estrategias aquí revisadas, como ya fue indicado, se encuentran imbricadas con los elementos previamente analizados, de tal manera que no es posible aislarlas de ellos. Por tanto, se intenta dejar en claro que de manera relevante tanto las formas que adquieren el trabajo productivo como el reproductivo al interior de las familias, aunado a sus condiciones materiales de vida, relacionadas de manera concreta principalmente con el tipo y características de la vivienda que ocupan, así como atravesadas por las determinantes sociales de clase, género, etnia, generación, ocupación, entre otras, se encuentran presentes en el marco donde se generan y desarrollan los procesos de salud-enfermedad, mismos que tienen un carácter indudablemente social e histórico.

De esa forma, la situación de salud tanto física como mental, así como los tipos y características de padecimientos enfrentados por la población están vinculados directamente con la ubicación de las personas y familias en la estructura social (Mallardi, 2018). De la misma manera que todo ello se evidencia en las principales causas de muerte en la población. Por tanto, es imprescindible ahondar en la revisión de la manera en que se articulan dichos elementos, en especial, las características que por lo general adoptan los procesos de enfermedad y muerte en la población, como consecuencia y/o impactos en la vida cotidiana marcada fuertemente por las determinantes sociales y con ello, en el efecto de la política social implementada durante las últimas décadas.

Por lo anterior, es ineludible la revisión del tema de transición demográfica enfrentado por la sociedad mexicana, el cual ha sido señalado como un doble proceso que se caracteriza inicialmente por una primera transición marcada fuertemente por el fenómeno de envejecimiento poblacional, cuyos detonantes han sido la disminución de las tasas de natalidad y de mortalidad (Asili, 2004.; CastiIlo, 2005; Ham-Chande, 1999 y 2003; Partida, 2005; Zavala, 2014). Se ha señalado que esa tendencia decreciente ha ocurrido como producto de la política pública, especialmente de la política social, tanto en el ámbito de salud, al ampliar los sistemas de atención médica a la población, así como la expansión de los servicios públicos que conllevan a mayores niveles de higiene y prevención de enfermedades infecciosas.

La transformación señalada se evidencia en los cambios de la pirámide poblacional durante las últimas décadas, así como en el incremento de la esperanza de vida en la población, lo que indica claramente el aumento gradual de las generaciones de personas adultas mayores y la disminución proporcional de las de menor edad, ello repercute en mayores índices de envejecimiento, aun cuando México sigue siendo un país predominantemente joven (véase Tabla 2). 
Gráfica 3. Principales causas de mortalidad en hombres y mujeres 2017, porcentaje.

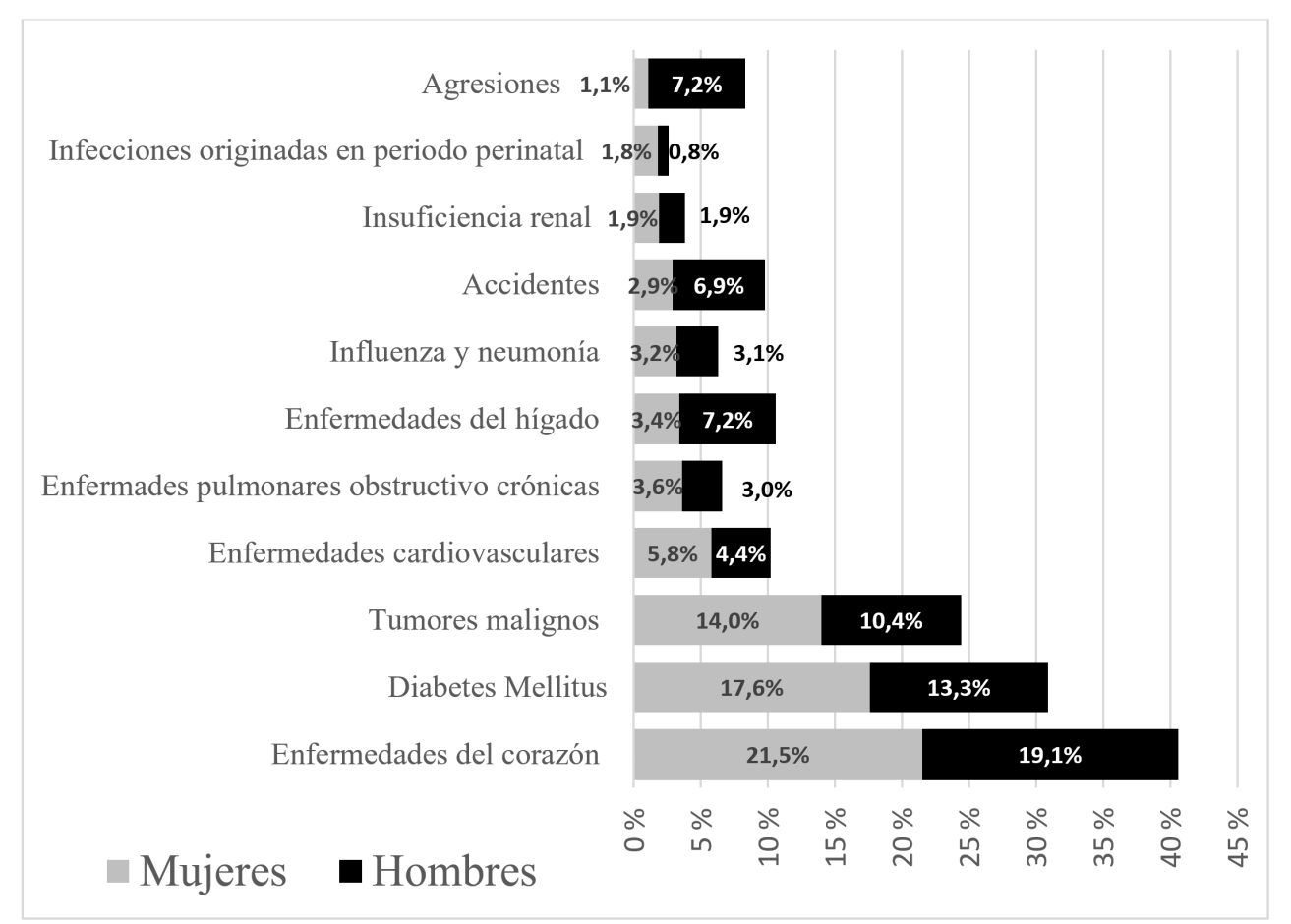

Fuente: INEGI Estadísticas de mortalidad. Consulta interactiva de datos.

Aunado a ello, confluye una transición epidemiológica, considerándose que esta consiste en el paso de enfermedades predominantemente infecciosas a las de tipo crónico-degenerativo, tanto entre las principales causas de morbilidad, así como de mortalidad. No obstante, al ser producto especialmente de la enorme heterogeneidad entre la población, así como la desigualdad presente entre las regiones y los grupos sociales, en el país dicho proceso más bien se ha constituido en una polarización epidemiológica; puesto que, si bien se evidencia un incremento de padecimientos crónico-degenerativos entre la población, en este caso siguen persistiendo las enfermedades de tipo infeccioso, especialmente en algunas regiones del país (Escobedo, 2013). Ello deja entrever que, si bien existe un claro proceso de envejecimiento demográfico asociado con diversos cambios sociales, económicos y políticos, no obstante, el mismo adquiere características particulares derivadas de la desigualdad social, así como del impacto de las determinantes sociales en los procesos de saludenfermedad de la población, mismos que se encuentran situados en términos históricos y sociales.

La segunda transición sociodemográfica, alude principalmente a los cambios observados al interior de las familias, especialmente en el papel de las mujeres y de los hijos; ello está asociado principalmente a la mayor escolaridad promedio de las mujeres, quienes presentan una disminución del número de hijos promedio, así como se incorporan en mayor medida al mercado laboral (Ariza y De Oliveira, 2004; Zavala, 2014). Aunado a ello, los hijos se constituyen en el centro de atención familiar y en una forma de satisfacción para los padres, a diferencia de generaciones anteriores en las que constituyeron especialmente un apoyo para las tareas tanto reproductivas como productivas. Por tanto, los cambios de esta segunda transición no solamente impactan en términos demográficos, sino particularmente en lo socio-simbólico, generando una significación distinta en el papel de las familias, centrando la atención en la pareja y el cuidado de los hijos, lo que impacta fuertemente la vida cotidiana de los grupos familiares.

La revisión de esa doble transición sociodemográfica se torna ineludible cuando se analiza la génesis de los problemas de salud, así como su articulación con el proceso social, lo que da cuenta del carácter sociohistórico de la enfermedad. En tanto las formas que adquiere muestran cambios significativos en el tiempo, lo que permite identificar el vínculo entre las transiciones señaladas, mismas que entrecruzan elementos históricos, sociales, demográficos, económicos, culturales y políticos. De tal forma que su intrincado vínculo genera impactos evidentes en la vida cotidiana familiar, dejando entrever la manera en que se entrelazan las determinantes sociales en el ámbito de salud de sus miembros.

En términos de salud, ha sido señalado por la literatura (Asili, 2004; Laforest, 2002; entre otros) que las mujeres suelen presentar en mayor medida enfermedades de tipo crónico-degenerativo, mientras que los varones, por el contrario, muestran en mayor medida problemas agudos que conllevan de forma rápida a la muerte. Ello ha sido señalado como parte de las explicaciones en torno a las diferencias de género con respecto a la situación de enfermedad, especialmente durante la vejez. Otro elemento que ha sido señalado para explicar esa brecha consiste en subrayar que la mujer acude de manera constante y oportuna a los servicios médicos, y por ello, es diagnosticada de manera más temprana que los varones, generando mayores posibilidades de que su padecimiento sea controlado, a 
Gráfico 4. Mujeres y hombres de 18 y más años por condición de práctica físico-deportiva en su tiempo libre en México, porcentaje

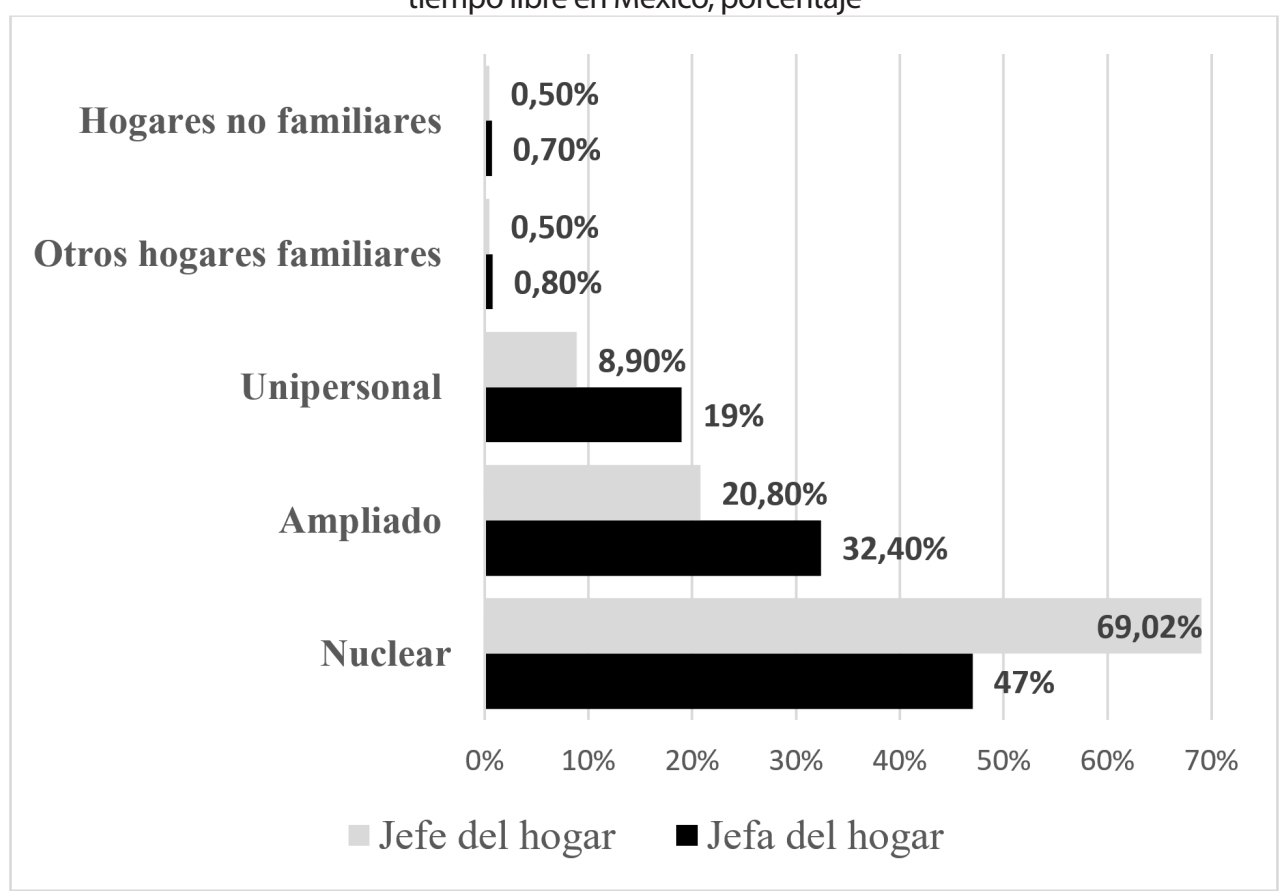

Fuente: INEGI (2018) Módulo de Práctica Deportiva y Ejercicio Físico (MOPRADEF).

diferencia de los hombres, que recurren al médico cuando el malestar es constante o intolerable, por lo general ante situaciones graves y agudas.

No obstante, esta explicación difiere de las evidencias obtenidas durante los últimos años, en tanto la distancia entre los géneros en términos de enfermedades se ha tornado difusa y cada vez más reducida. De esa manera, es posible comprender la transformación de las enfermedades en su relación con el género no alude a cuestiones solamente biológicas, sino principalmente sociales y que estas dan cuenta de situaciones enfrentadas por los grupos durante su trayectoria de vida. Al observarse las diferencias anteriormente presentes entre hombres y mujeres en términos de las causas principales de muerte, se advierte una tendencia actual a equipararse entre los mismos, presente en los datos referidos a los últimos años. Ello parece derivarse en parte de las crecientes tensiones al interior de la familia, en particular la sobrecarga enfrentada por las mujeres, quienes han visto incrementarse sus jornadas de trabajo, en especial, luego de incorporarse al mercado laboral, a la par de enfrentar jornadas de doble cuidado (a varias generaciones de manera alterna). Ello ha traído fuertes implicaciones en la vida cotidiana de las familias, particularmente un mayor estrés y desgaste en las mujeres, lo que por una parte, genera nuevos y/o mayores problemas de salud, visible en el equiparamiento de los padecimientos mostrados por hombres y mujeres (véase Gráfico 3).

De manera paralela, se advierte que la diferencia entre géneros con respecto a la esperanza de vida también se va reduciendo. Otro aspecto que impacta, especialmente a las mujeres es la dificultad para crear, mantener y/o fortalecer sus redes de apoyo, puesto que los tiempos se complican cada vez más, de tal forma que las relaciones sociales, no solo presentes, sino también a mediano y largo plazo, se ven seriamente afectadas. Lo último se encuentra claramente vinculado con la feminización del cuidado y en especial, con la triple jornada laboral, que reduce drásticamente las posibilidades del recurso de tiempo en el caso del género femenino. Esto a su vez, tiene claras repercusiones en la salud, tanto en la física como en la mental, derivada en gran medida del curso de vida de los sujetos, en especial de las condiciones en las que ocurren sus trayectorias y, por tanto, las determinantes sociales del proceso de salud-enfermedad.

6. Estrategias de socialización, aprendizaje y uso del tiempo libre

Si bien este tipo de estrategias al igual que las anteriores evidencian grandes tensiones e incluso conflictos entre sus miembros, en este caso particular, las mismas suelen estar definidas en gran medida por la manera en que la familia alcanza a mediar entre sus miembros y la sociedad en la que está inmersa, lo que está definido en gran parte por las necesidades de sus miembros y los dispositivos que se derivan de las normas sociales.

Ello suele estar vinculado a su saber en torno a lo cotidiano y sus valores morales respecto a la reproducción familiar, así como con sus recursos disponibles, particularmente los de tiempo. Estas estrategias definen hasta cierto punto la toma de decisiones y el marco organizativo 
en que las mismas se dan, asociadas con la organización y división de tareas, particularmente entre géneros y generaciones. Por tanto, en la vida cotidiana de las familias se presentan algunas de las tendencias universales, particularmente una constante relación dialéctica entre lo singular y lo universal, lo que finalmente produce una síntesis, evidente en lo cotidiano de cada miembro de la familia y en cada arreglo familiar (Mallardi, 2018).

De esa manera, los recursos y saberes de la vida cotidiana están constituidos por aquellos conocimientos sobre la realidad que han sido interiorizados y que permiten desenvolverse en la cotidianeidad. Lo cotidiano a su vez conforma un proceso de gran complejidad en el cual confluyen determinaciones sociales e históricas impactando fuertemente a los sujetos y sus familias. Por tanto, también están relacionadas con la inserción y participación de sus miembros en instancias extrafamiliares como son el trabajo, la escuela, la asistencia social, entre otras.

La disposición de tiempo libre y el uso que se hace del mismo es una situación marcada fuertemente por el género, en tanto las mujeres, como ya fue señalado en los epígrafes anteriores, se encuentran sobrecargadas, contando en promedio con menores recursos de tiempo para sí mismas, un claro ejemplo de ello es la realización de deporte, señalado como uno de los recursos de gran relevancia para la salud física y mental (véase Gráfico 4).

Como se puede observar en el Gráfico 4 las mujeres realizan deporte en menor proporción que los varones, lo cual está relacionado con el recurso del tiempo disponible y su aplicación, en el caso de las mujeres, principalmente para cuidar de otros y asumir la responsabilidad en las tareas domésticas. Otro aspecto que determina en parte la manera del uso del tiempo libre, incluso del tiempo en general y hasta las posibilidades de mantener el contacto con parientes y/o amistades es el acceso y uso de tecnologías digitales, las cuales especialmente ante el contexto de confinamiento por pandemia enfrentado el último año, marca profundas brechas entre los grupos sociales, atravesadas por las determinantes sociales de género, clase, contexto de residencia y generación a la que se pertenece, marcando altos niveles de exclusión para algunos de estos grupos entre los que destacan las mujeres, particularmente las de mayor edad, residentes en contextos rurales, así como de habla indígena y migrantes.

\section{Conclusiones}

En síntesis, lo anterior deja entrever las numerosas y crecientes tensiones, ambivalencias y conflictos enfrentados durante las últimas décadas por la diversidad de arreglos familiares, mismos que enfrentan esta situación ante la tensión procedente en muchos casos, por la ambivalencia y contradicciones presentes entre las presiones internas, derivadas de las necesidades de los miembros, tanto de tipo material, como también no material (afectivas, de compañía y escucha, cuidados, entre otras) y aquellas a las que se responde, por lo general de una forma particular y en ocasiones específica, constituidas por las demandas derivadas del contexto socio-histórico, mismas que se encuentran atravesadas por las determinantes sociales: de género, generacionales, culturales, económicas, entre otras, derivadas incluso de las políticas sociales que definen la medida y forma de acceso a los derechos sociales como la alimentación, atención médica, seguridad social, vivienda, servicios públicos, trabajo e ingreso, así como a las relaciones sociales, formales e informales, elemento crucial de la cohesión social.

Por tanto, cada familia desarrolla e implementa estrategias muy diversas que permiten responder tanto a las presiones internas como externas y eso define en parte sus características y particularidades, lo que además es implementado a partir de los recursos y conocimientos de sus miembros. Por lo tanto, no es posible homologar, ni esperar que la respuesta familiar suceda de una misma forma entre los grupos familiares. Sin embargo, dicha respuesta no es algo totalmente libre o espontáneo, sino siempre circunscrito a las demandas de su contexto económico, político, social y cultural, definido a partir de las determinantes sociales que atraviesan a estos grupos.

Las transformaciones observadas durante las últimas décadas tienen, por tanto, no solamente un trasfondo demográfico y social, sino constituyen principalmente un producto sociohistórico con fuerte base económica y política. Es decir, se derivan de la confluencia entre presiones derivadas del sistema productivo, como maquinaria organizadora de los grupos sociales, especialmente en términos del trabajo, priorizando el de tipo productivo y relegando, además de invisibilizar al de tipo reproductivo. Dicha situación, conlleva una fuerte carga para los arreglos familiares, repercutiendo fuertemente en su organización, recursos, papel, entre otros, es decir, su vida cotidiana, en tanto dicha situación es incorporada también en las subjetividades y las formas de interacción social.

Por tanto, las tensiones en las familias se ven recrudecidas en torno a la vinculación entre dos aspectos esenciales: el trabajo productivo y el reproductivo; de tal manera que conjugar ambos elementos de manera general y las estrategias vinculadas para responder a ellos, de manera particular se constituye en unas de las principales tensiones y/o conflictos a enfrentar, al encontrarse estas cargadas de ambivalencias y contradicciones. Ello se evidencia en torno a elementos como el tipo de trabajo que se desarrolla, el acceso a seguridad social y contar con protección social; lo que a su vez está atravesado por determinantes sociales como ya se indicó; pero también por las políticas públicas y sociales, mismas que a partir de programas y proyectos específicos demandan respuestas particulares ante situaciones generales y mandatos morales, lo que es considerado desde la agenda pública como responsabilidad de la familia, omitiéndose la corresponsabilidad del Estado en torno al bienestar social de los miembros del grupo familiar, así como al interior del hogar entre los miembros participantes.

Por otro lado, la situación de crisis sanitaria enfrentada durante el último año por motivo de la pandemia por COVID-19 deja entrever un recrudecimiento de las brechas 
sociales preexistentes a la misma, evidente ello en la exacerbada desigualdad entre los grupos sociales, que si bien ya era evidente, ahora se profundiza, generando mayores niveles de exclusión social en algunos de ellos, lo que se encuentra atravesado por las determinantes principalmente de género, clase, etnia, ocupación, tipo de trabajo, contexto de residencia y generación a la que se pertenece.

Es necesario como señala Mallardi (2019) profundizar en la comprensión de los procesos históricos, sociales, económicos y políticos que impactan de manera objetiva y subjetiva la vida cotidiana de las familias, analizando de forma amplia y dialéctica las estrategias familiares de vida, mismas que son trastocadas en situaciones de crisis, como la crisis sanitaria y social que enfrentamos actualmente por la pandemia de COVID-19. Dichas estrategias además de verse alteradas, confrontadas, se encuentran hasta cierto punto impedidas al ser resignificadas algunas de sus dimensiones.

Por tanto, es de gran relevancia que el análisis de la situación familiar y sus transformaciones sea realizado desde una visión crítica que permita develar lo concreto como una síntesis de la complejidad presente en las múltiples determinantes y su vinculación, así como de la manera en que estas se entretejen en la vida cotidiana. Para Guerra (2017) es imprescindible partir del análisis histórico, particularmente de las contradicciones presentes, de tal forma que ello permita una visión que supere el carácter técnico y funcional que sesga los resultados. Por tanto, es indispensable incorporar una concepción dialéctica de la situación enfrentada por las familias, concebida como proceso de continuidades y rupturas que da cuenta de la esencia, para ver más allá de la apariencia planteada por la razón instrumental, que simplifica la realidad para ubicarla dentro del orden hegemónico vigente.

\section{Bibliografía}

ARIZA, M. y DE OLIVEIRA, O. (2004): “Universo familiar y procesos demográficos", en M. Ariza y O. De Oliveira (coords.), Imágenes de la familia en el cambio de siglo. México, Instituto de Investigaciones sociales y Universidad Nacional Autónoma de México, pp. 9-45.

ARIZA, M. y DE OLIVEIRA, O. (2001): “Cambios y continuidades en el trabajo, la familia y la condición de las mujeres", en E. Urrutia (coord.), Estudios sobre las mujeres y las relaciones de género en México: aportes desde diversas disciplinas. México, El Colegio de México, pp. 43-86.

ARRIAGADA, I. (2007): "Transformaciones familiares y políticas de bienestar en América Latina", en I. Arriaga (coord.), Familias y políticas públicas en América Latina. Una historia de desencuentros. Santiago de Chile, Naciones Unidas y Comisión Económica para América Latina y el Caribe CEPAL, pp. 125-153. https://repositorio.cepal.org/ bitstream/handle/11362/2505/S0700488_es.pdf.

ARRIAGADA, I. (2005): “¿Existen políticas innovadoras hacia las familias latinoamericanas?", Papeles de Población, 43, pp. 9-27. https://www. redalyc.org/pdf/112/11204302.pdf.

ARROYO, M. (2009): Dependencia y cuidados en la vejez avanzada de hombres y mujeres en la ciudad de Durango. Un análisis de subjetividad y la formación de identidades. Tesis para optar por el grado de Doctor en Filosofía con orientación en Trabajo Social y Políticas comparadas de bienestar social. Monterrey, Universidad Autónoma de Nuevo León, https://cd.dgb.uanl.mx/handle/201504211/16365.

ASILI, N. (2004): Vida plena en la vejez. México, Editorial Pax.

CABOT, R. (2008): “Ensayos de Medicina social. La función de la inspectora a domicilio", en Trabajo Social y Salud. Zaragoza, Escuela Universitaria de Estudios Sociales, pp. 25-174.

CASTILLO, D. y VELA, F. (2005): “Envejecimiento demográfico en México. Evaluación de los datos censales por edad y sexo, 1970-2000", Papeles de población, 45, pp. 107-141. http://www.scielo.org.mx/pdf/pp/ v11n45/v11n45a6.pdf.

CEPAL (2021): Mortalidad por COVID-19. Evidencias y escenarios. Observatorio demográfico América Latina y el Caribe. Santiago, Naciones Unidas y Comisión Económica para América Latina y el Caribe. https://repositorio.cepal.org/bitstream/handle/11362/46640/5/ S2000898_es.pdf.

CEPAL (2016) Autonomía de las mujeres e igualdad en la Agenda de Desarrollo Sostenible. XIII Conferencia Regional sobre la Mujer en América Latina y el Caribe. Montevideo, Naciones Unidas. Comisión Económica para América Latina y el Caribe. https://repositorio.cepal. org/bitstream/handle/11362/40633/4/S1601248_es.pdf.

DE RISO, S. (2001): "Familias y crisis en el fin de siglo: permanencia y cambio", en E. De Jong, R. Basso y M. Paira (coords.), La familia en los albores del nuevo milenio. Buenos Aires, Editorial Espacio.

ESCOBEDO, J. M. (2013): "Transición epidemiológica de México y la evolución de su mortalidad", en VII Jornadas de Jóvenes Investigadores. Buenos Aires, Instituto de Investigaciones Gino Germani. https:// www.aacademica.org/000-076/324.pdf.

GARCÍA, B. y DE OLIVEIRA, O. (2004): "Trabajo extradoméstico femenino y relaciones de género: una nueva mirada", Estudios demográficos y Urbanos, 55, pp. 145-180. https://www.redalyc.org/ pdf/312/31205504.pdf.

GUERRA, Y. (2017): “La fuerza histórico-ontológica y crítico analítica de los fundamentos", en Y. Guerra, Trabajo social: fundamentos y contemporaneidad. La Plata, Instituto de Capacitación y Estudios Profesionales/Colegio de Trabajadores sociales de la provincia de Buenos Aires, pp. 17-52 https://www.mitrabajoessocial.com/trabajo-socialfundamentos-y-contemporaneidad-yolanda-guerra/.

HAM CHANDE, R. (1999): “El envejecimiento en México: de los conceptos 
a las necesidades", Papeles de Población, 19, pp. 7-21, https://www. redalyc.org/pdf/112/11201902.pdf.

HAM CHANDE, R. (2003): "Envejecimiento demográfico. Sin soluciones sobre la sobrevivencia decorosa de la población mayor", Demos, 16, pp. $42-43$.

INMUJERES (2018): Las madres en cifras. Gobierno de México, Instituto Nacional de las Mujeres, en línea https://www.gob.mx/inmujeres/ articulos/las-madres-en-cifras.

INMUJERES (2015): Sistema de indicadores de género. Cálculos con base en la Encuesta intercensal INEGI. Instituto Nacional de las Mujeres. En línea, http://estadistica.inmujeres.gob.mx/formas/panorama_ general.php? menu $1=2 \& \mid$ DTema $=2 \&$ pag $=1$.

INEGI (2020): Resultados del Censo 2020 en México por tema de interés. Instituto Nacional de Estadística, Geografía e Informática. En línea, https://censo2020.mx/resultados-por-tema-de-interes/ https:// www.inegi.org.mx/temas/hogares/.

INEGI (2018): Encuesta Nacional de la Dinámica Demográfica. Aguascalientes, Instituto Nacional de Estadística, Geografía e Informática.

LAFOREST, J. (2002): Introducción a la gerontología. El arte de envejecer. Barcelona, Editorial Herder.

LAGARDE, M. (1993): Los cautiverios de las mujeres: madresposas, monjas, putas, presas y locas. México, Universidad Nacional Autónoma de México https://desarmandolacultura.files.wordpress.com/2018/04/ lagarde-marcela-los-cautiverios-de-las-mujeres-scan.pdf.

LAMAS, M. (1996): "La antropología feminista y la categoría "género"', en M. Lamas (comp.), Género: la construcción cultural de la diferencia sexual. México, PUEG, pp. 97-126. https://www.legisver.gob.mx/ equidadNotas/publicacionLXIII/El\%20genero.\%20La\%20construccion\%20cultural\%20de\%20la\%20diferencia\%20sexual.pdf.

MALLARDI, M. (2018): Informe social y relaciones familiares. Categorías en disputa. Buenos Aires, PUKA. https://pukaeditora.mercadoshops. com.ar/MLA-787820635-informe-social-y-relaciones-familiarescategorias-en-disputa-_JM?variation $=37527807234 \&$ quantity $=1 \mathrm{Hr}$ eco_item_pos=3\&reco_backend=machinalis-seller-items\&reco_ backend_type=function\&reco_client=vip-seller_items_aboveshops\&reco_id=d98bf8a9-b536-4bab-a655-b8be9faa49c8.

MALLARDI, M. (2019): "Fundamentos y determinaciones sociohistóricas de la cuestión social", en M. Mallardi y E. Fernández, Cuestión social y Políticas sociales. Crítica a sus fundamentos y expresiones contemporáneas. Buenos Aires, Editorial PUKA. Capítulo I, pp. 15-44 https:// es.scribd.com/document/472276198/Cuestion-social-y-politicassociales-Puka-Editora.

MENDOZA, L. (2016) Situación crítica laboral e ideología de género: su incidencia sobre la reacción ante el conflicto y la autoridad en los hogares monoparentales con jefatura femenina. Tesis presentada para obtener el grado de Doctor en Filosofía con orientación en Trabajo Social y Políticas comparadas de Bienestar social en la Universidad Autónoma de Nuevo León https://rediab.uanl.mx/Record/ eprints-2592.

PARTIDA, V. (2005): "La Transición demográfica y el proceso de envejecimiento en México", Papeles de población, 45, pp. 9-27. https://www. redalyc.org/pdf/112/11204502.pdf.

POXTAN, M. (2010): Familias monoparentales con jefatura femenina en México. Tesis presentada para obtener el grado de Maestría en Ciencias con orientación en Trabajo Social. http://eprints.uanl.mx/2228/

RENDÓN, T. (2008): Trabajo de hombres y trabajo de mujeres en el México del siglo XX. $2^{\text {a }}$ edición. Cuernavaca, PUEG. https://www.crim. unam.mx/web/publicacion/trabajo-de-hombres-y-trabajo-de-mujeres-en-el-m\%C3\%A9xico-del-siglo-xx-0.

RIBEIRO, M. (2010): “Cambios sociales y transformaciones familiares en Monterrey", en C. Contreras, V. Zúñiga, T. Blös, D. Mercier, V. Baby-CoIlin y C. Sheridan (coords.), Cuando México enfrenta la globalización. Permanencias y cambios en el área metropolitana de Monterrey. Monterrey, Universidad Autónoma de Nuevo León y Colegio de la Frontera Norte, pp. 189-213 https://libreria.colef.mx/detalle.aspx?id $=7216 \&$ AspxAutoDetectCookieSupport $=1$.
RIPOL, A. (2001): Familias, trabajo social y mediación. Barcelona, Editorial Paidós.

TAMEZ, B. y ZÚÑIGA, M. (2016): “Análisis de la pobreza multidimensional en familias monoparentales con jefatura femenina y propuesta de intervención social desde la visión crítica", en Martha Cabello y Martín Castro (coords.), La intervención en Trabajo Social. Enfoques, problemas y alternativas para el desarrollo humano. Monterrey, Universidad Autónoma de Nuevo León/ACANITS, pp. 23-55.

TAMEZ, B. (2020): Envejecer con dependencia situación diferencial entre contextos urbanos y rurales de Nuevo León. Monterrey, Universidad Autónoma de Nuevo León.

TAMEZ, B. (2008): La solidaridad familiar hacia los adultos mayores en Monterrey, N. L. Monterrey, Instituto Estatal de las Mujeres en Nuevo León. https://www.nl.gob.mx/sites/default/files/interioresadultosmayores.pdf.

ZAVALA, M. E. (2014): "La transición demográfica en México (1895-2010)", en Cecilia Rabell, Los mexicanos Un balance del cambio demográfico. Fondo de Cultura Económica, pp. 80-114. https://halshs.archivesouvertes.fr/halshs-00968364/document. 